when spoken to in a loud voice; said she felt faint and a aitble sick. She vomited once, and retched a good deal. In looking at her as she lay on the shady side of the badly lit room there was nothing to attract particular attention. The was not at all restiess, and had scarcely any pains. She had lost about a pint of blood. I had a good light thrown wn her face. It was quite white, the lips being of a pale ashen colour. She was quite pulseless on both sides. The heart was beating 148 to the minube, but only one sound, apparently the second, could be heard. The uterus was very tense; the os as big as a crown-piece, easily dilatable; the head in the fourth position; the membranes anruptured; no placenta to be felt. Recognising her almost hopeless condition, and that she was bleeding internally, I at once ruptured the membranes, a considerable quantity of bloody fluid escaping. I then applied the forceps and easily delivered the child, without rupturing the perineum. The body was easily extracted, and was followed by the placenta and some large adherent and loose clots, and, I should say, a pint and a half of fluid blood. The uterus contracted well and remained hard, with the exception w a momentary relaxation which permitted the escape of a couple of ounces of blood. The patient was now a little restless. The head was lowered, the legs raised and bandaged, the binder tightly applied, and brandy given her. Once or twice she raised her arm above her head and partlv rolled over, and said quiebly "Can't I have some air?" She now became deaf and rapidly became unconscious. The pupils were moderately small, as they had been all along. I at once opened a vein in the right arm. When the cut was made through the skin she murmured, "Who's that pinching me ?" and then lay quite quiet as if dead. Before two ounces had been injected her face became set with a hideous grin, lastlng a few seconds; then a few clonic contractions of the face and alight ones of the arms and legs appeared, and she was dead.

$$
\text { (To be concluded.) }
$$

\section{A MODIFICATION OF THE OPERATION OF RABTIAL OR COMPLETE EXCISION OF THE TONGUE.}

BY W. ARBUTHNOT LANE, M.S.,

ASSISTANT SURGEON TO GUY'S HOSPITAL AND TO THE HOSPITAL FOR SICK CHILDREN, GREAT ORMOND-STREET.

THe suggestion which I am going to make in this brief communication is possibly one that is already familiar to some surgeons; but as I have never seen it nsed or heard of its use, I think it is of sufficient importance to bring it before the profession. Though it is but a trifling modification of the usual methods adopted, I have found it of the very greatest service not only in diminishing the pain and diseomfort which are usually experienced by the patient after these severe operations on the tongue, but also in lessening she danger of pneumonic trouble by the small amount and inoffensive character of the discharge, and in hastening very considerably the process of recovery. The mucus which collects in the mouth and pharynx can also be removed without the patient experiencing any considerable pain, since the sponge is not applied to any raw and sensitive surface. In some cases also the patient retains a fair proportion of the sense of taste. In the case of removal of a half of the tongue the suggested modification consists in the very accurate ;aturing of the cut margin of the mucous membrane on the dorsum of the tongue to the edge of that corering the floor of the mouth in such a manner that no raw surface is left ancovered by mucous membrane. In some cases it is neces. sary to alter the form of the portion of the tongne left, so as to make it fit the gap left with perfect accuracy. This ig, however, easily met by a litble ingenuity, and assistance may often be obtained by loosening the mucous membrane from the floor of the month and gam. When it is necessary to remore the body of the tongue, after carefully defining the extreme limits of the growth and giving it a wide smargin, a large flap of mucous membrane with a substratum of muscular tissue is sliced off from that portion of the tongue which is of a cerbainty free from growth, and this hap is accurately sutured with fine silk sutures to the free margin of the mucous membrane in the floor of the mouth, and to that covering the roov of the tongue, is such a manner as to cover the whole of the raw surface of cub muscle which is left exposed by the removal of the tongue. This procedure would, of course, not be adopted if there was any chronic inflammation of the mucous membrane, which might form the starting-point of malignant disease; buteven in these cases the mucous membrane covering the under-surface of the tongue is probably unaffected, and it is surprising how large an area of raw surface a small portion of mucous membrane can be made to cover. The very vascular flap of muscle and mucous membrane unites with remaskable rapldity to the subjacent raw surface, and in this manner within a few hours of the operation the floor of the mouth is covered by a smootb layer of mucous membrane, instead of by a large inflamed or granulating ares discharging abundantly a secretion which rapidly decomposes, and which may be, and often is, readily sucked into the larynx and air passages, where it produces trouble with which we are only too familar.

As illustrations of the mode of application of this method I will give only two cases, the following brief descriptions of which are, I think, sutficient to indicate its advantages. J. S-, aged fifty, was admitted into Job ward under my care on June 26th, 1890, suffering from a deep epithelio. matous ulcer in the right margin of the tongue in the middle third of that organ. The growth had started in a gumma which had not been treated. There were two or three small glands to be felt in the right submaxillary triangle. These were removed and the lingual artery was tied. The right half of the tongue was removed, with the exception of a portion of its posterior part. The remainder of the tongue was so altered in shape by small incisions that when the mucous membrane covering its dorsum and under surfaces was attached by sutures to that covering the stump of the right half of the tongue and that lining the inner half of the right half of the body of the jaw no raw surface was left exposed. Within forty-eight hours of the operation these margins appeared to have united. Certainly at no period did any gaping or yielding take place along the lines of suturing. The well-being of the patient after the operation, as regarded freedom from discomfort or pain, the absence of discharge, the ready manner in which mucus could be painlessly, or almost painlessly, removed by sponges from the mouth and throat, together with the very rapid convalescence, was remarkable as compared to the usual course pursued by such casea.

T. O'B_-, aged forby-five, was admitted into Job ward, under my care, on Dec. $9 \mathrm{th}, 1890$, suffering from an ulcersting epitheliomatous growth involving about a third of the diameter of the tongue in its midale third, and extending slightly over its margin to the mucous membrane covering the floor of the mouth. A small gland could be felt in the submaxillary region on the same side. On Dec. 19th the right lingual artery was tied, and three small glands were removed from the submaxillary region. Eight days after. tracheotomy having been performed, the right cheek was split back to the anterior margin of the masseter in order that free access might be obtained to the floor of the mouth on that side. A carefully-planned flap of mucous mem. brane and muscle was then cut from the left side and tip of the tongue, every care being taken to keep at what appeared to be a perfectly safe distance from the margin of the growth. The rest of the tongue was next removed, and the flap was then accurately sutured into the floor of the mouth by means of silk sutures, which attached it to the divided margin of mucous membrane both in the floor of the mouth and along the alveolar margin, where it was necessary to remove the mucous membrane covering the floor and to that covering the closure of the stump of the congue posteriorly. The subsequent course of this case was quite as satisfactory as that of the preceding.

I have used this method on several occasions, and in every case I have felt myself very well repald for the time and trouble spent in perfecting the operation, and if used with discretion I can see no circumstances under which it could be other than of the greatest benefit to the patient. The increased duration of the operation is of very slight moment as compared to the advantages obtained by it, and in order to ensure the accurate approximation of the divided edges I do not hesitate to split the cheek or perform tracheotomy, although either of these measures might be unneces sary if one were satisfied with the ordinary mode of excision. The benefit gained counterbalances the slight extra risk.

Since writing this I have read the account of an operation 
by Dr. Widenham Mansell, for excision of the tongue In leacoplakia or cancer and the utilisation of a portion of the under surfase of the organ to fill accurately the gap with the best possible results.

St. Thomas's-street, S E.

\section{SCORBUTIC H EMATURIA IN AN INFANT.}

By JOHN THOMSON, M.D., F.R.C.P. EDIN., EXTRA-PHYSICIAN TO THE ROYAL HOSPITAL FOR SICK CIIILDREN, EDINBURGII.

The following case seems worthy to be put on record, as being an example of an extremely rare type of infantile scurvy. The clinical facts are as follows.

J. E_-, aged seven months, brought from Leith on Feb. 11th, 1892. The infant has been losing flesh and energy for two months, and for the last month his urine has been red. The parents are healthy and toler ably well. to.do. They are very careful of the infant, and his home surroundings seem, on inquiry, to be quite satisfactory from a hyglenic point of view. At birth he seemed quite strong and healthy. From birth to the present time he has been given condensed milk. Daring the first week of Jife he had nothing else. Then for a month or two months he had barley-wacer added to it. After that for about ten days he was given a little raw meat juice along with the condensed muk; but he did not like it, and io was therefore stopped. When the raw meat juice was abandoned (four months ago) he was given a pancreatised "Infant's food," and on thao, along wich condensed milk and water, he has been fed exclusively siace. He has been in the habit of romiting about half of the food given to him. His bowtls bave al ways been regular and norma. in their action. Of late be has been very restless a night; he has always sweated very freely on his head. $\mathrm{He}$ has never before had any illness, except that he was "feverish" and had a sligho cough when his teeth appeared. About two months ago the intant was noticed to be very languid and to be gettung thinner and paler. This has gone on steadily increasing. At the beginning of January the father, who was eating an orange, held it out to the infant. He made a wry face ao first when he put his lips to it, but immediately atterwards be clutched hold ot the orange with both his hande, and would not give it up until he had sucked a considerable amount of the juice. After doing this he was very sick. The parents were amused at his eagerness to suck tile orange, but they thought they had made him ill by letting him have 10, and therefore they have never allowed tim to have any thing of the kind since. About a month ago the urine was noticed to be bright red, and it has remained so ever since. The infant has suffered no pain of any kind, $t$ xcept occasionally "from wind." No special tenderness or pruise of any part has ever been noticed.

The infant is vely languid and listless, with a pale, yellowish, earthy cowplexion; the gums are pale, and nov at all swollen, and thele are no ecchymoses on them. The lower central incisors are the only teeth through the gum. The fontanelle is large and the ribs beaded, but there are no further signs of rickets. The abdomen is normal ; no tumour is to be felt, and the liver and spleen are not enlarged. The heart and lungs are normal ; temperature also normal. There is no distinct tenderness anywhere on palpation or passive movement, but the child evidently dislikes being pulled about. There is no ecchymosis, and no swelling of any bone, or joint, or other pait. The urine is of a bright-red colour. On standıng, a copious reddish deposit takes place, but the clear urine which is left remains bright red; reaction acid. Mach albumen found on testing with nitric acid and bolling. On wicroscopical examination the deposit is found to consist almost entirely of red bloodcorpuscles. There are also a few leucocytes and blood. plates, but no tube casts, and nothing else of importance. The case was diagnosed as scorbutic hæmaturia due to improper feeding. The infant was ordered to have nothing buo the following diet: (1) As much fresh cow's milk and barley water (equal purts) as he will take, every three or four hours; (2) a dessertsponnful of raw meat juice

1 A New Meth d of Excising the Tongue. (Read at the New Zealand Medical Association, Dunedin, 1890.) (prepared as advised by Dr. Cheadle) thrice daily ; (3) a dessertspoonful of orange juice twice daily. No medicine. Feb. $18 \mathrm{oh}$ : For some reason the dlet recommended was not given until the evening of the $13 \mathrm{bh}$. On the 14 th the urine was quite free from any red colour, for the first time for a month. On the 15 th it was somewhat pink, but since then it has been quite free from any tinge of red. It is now found on examination to be perfectly normal in appearance: there is not a trace of albumen, and no deposit is seen with the naked eye or under the microscope. The mother reports that the child is " very much better." He sleeps better, is more satisfied with his food, and has stopped vomiting altogether. $\mathrm{He}$ is also "much cheerier." His complexion has improved greatly, and he kicks about his legs while being examined in a healthy way which contrasts strongly with his former lassitude. - 21st : Improving in every way. "Just very well." Urine remains quibe clear. - 29th: Still improving in every respect except that he is somewhat restless at night and sweats a little on the head. Ordered cream, to be added to the milk, and cod-liver oil emulsion. March 14th : Sleeps well ; sweating stopped. Oat flour once daily. -24 th : Very well in every respect; has cut two upper incisors. - May 5 th : Has continued to gain steadily in strength since last note, and now has a rosy complexion, firm limbs, and the general appearance of a thoroughly healtby child.

Remarks - The specially interesting and, so far as I know, unique feature of this case is the fact that, with the excep. tion of the general lassitude, the bæmaturia was the only apparent manifestation of scorbutus present. And yet there cannob surely be any doubs whatever about the diagnosis, in spite of the entire absence of sponginess of the gums, periosteal hæmorrhages, and the other well-known signs. Hrmaturia is a recognised symptom of infantile scurvy, although one which is meb with only in a small proportion of cases. Dr. Cheadle reports ${ }^{1}$ a case of "obstivate and unexplained hæmaturia," vesy like this one, which, however, was found to be associated with ecchymoses, cedema of the limbs, and sponginess of the gums, and which was clearly scorbutic. The absence of spongy gums in this case does not militate against the diagnosis, for not only is this condition not met with where were are no teeth, but Dr. Barlow has published ${ }^{2}$ an undoubted ease of scurvy in which two incisors had appeared (as in this case), yet the gums were quite unaffected. The diet in my case was one well fitted to produce scarvy. The child's craving for the juice of an orange is an interestirg incident, and tends to confirm the diggnosis. A similar craving in an infant with scurvy, who clutched hold of an orange which was offered to it, and "then proceeded to souse its lips and nose in the juice," has recently been recorded by Dr. Northrup of New York ${ }^{3}$ Finally, we have here, in a marked and satisfactory degree, the "most important diagnostic of all, definite and rapid amelinration by anti. scorbutic regimen" (Barlow).

Edinburgh.

A REPORT ON THE

COMPLETE ABANDONMENT OF THE OPERA. TION FOR REMOVING CALCULI ENTIRE FROM THE BLADDER,

AND THE METHODS EMPLOYED INSTEAD, AT THE CIVIL HOSPITAL, HYDERABAD, SINDH.

BY SuRG.-MA JOR J. FORBES KEITH, M. D. \& C.M.ABER, CIVIL SURGEON AND SUPERINTENDENT, MEDICAL SCHOOL.

(Concluded from p. 1235.)

The second method: perineal lithotrity.-When the dis. meter of the stone is too large for the screw of the largest lithotrite the urethra can readily admit, then recourse is had to the second or perineal method or perineal lithotrity. It is only a modification of the first method, which may be distinguished as "urethral" in contradistinetion to "perinesl." I do not think it will be considered a waste of valuable time to briefly review the various incidents which

1 Artificial Feeding and Food Disorders of Infants, p. 193 2 Article "Scurvy" in Keating's Cyclopædia of Diseases of Children vol, ii. $p .269$.

vol. ii., p. 269.3 Archives of Pediatrics, Jan., 1892, p. 5. 